\title{
Influence of experience and the surgical learning curve on long-term patient outcomes in cardiac surgery
}

Bryan M. Burt, MD, ${ }^{\mathrm{a}}$ Andrew W. ElBardissi, MD, MPH, ${ }^{\mathrm{b}}$ Robert S. Huckman, PhD, ${ }^{\mathrm{c}}$ Lawrence H. Cohn, MD, ${ }^{\mathrm{b}}$ Marisa W. Cevasco, MD, ${ }^{\mathrm{b}}$ James D. Rawn, MD, ${ }^{\mathrm{b}}$ Sary F. Aranki, MD, ${ }^{\mathrm{b}}$ and John G. Byrne, MD

\section{ABSTRACT}

Objective: We hypothesized that increased postgraduate surgical experience correlates with improved operative efficiency and long-term survival in standard cardiac surgery procedures.

Methods: Utilizing a prospectively collected retrospective database, we identified patients who underwent isolated coronary artery bypass grafting (CABG) $(\mathrm{n}=3726)$, aortic valve replacement $(\mathrm{AVR})(\mathrm{n}=1626)$, mitral valve repair $(\mathrm{n}=731)$, mitral valve replacement $(\mathrm{MVR})(\mathrm{n}=324)$, and MVR + AVR $(n=184)$ from January 2002 through June 2012. After adjusting for patient risk and surgeon variability, we evaluated the influence of surgeon experience on cardiopulmonary bypass and crossclamp times, and long-term survival.

Results: Mean surgeon experience after fellowship graduation was $16.0 \pm 11.7$ years (range, 1.0-35.2 years). After adjusting for patient risk and surgeon-level fixed effects, learning curve analyses demonstrated improvements in cardiopulmonary bypass and crossclamp times with increased surgeon experience. There was marginal improvement in the predictability $\left(R^{2}\right.$ value) of cardiopulmonary bypass and crossclamp time for CABG with the addition of surgeon experience; however, all other procedures had marked increases in the $R^{2}$ following addition of surgeon experience. Cox proportional hazard models revealed that increased surgeon experience was associated with improved longterm survival in AVR (hazard ratio [HR], 0.85; $P<.0001$ ), mitral valve repair (HR, 0.73; $P<.0001)$, and MVR + AVR (HR, 0.95; $P=.006)$ but not in CABG (HR, 0.80; $P=.15$ ), and a trend toward significance in MVR (HR, $0.87 ; P=.09)$.

Conclusions: In cardiac surgery, not including CABG, surgeon experience is an important determinant of operative efficiency and of long-term survival. (J Thorac Cardiovasc Surg 2015;150:1061-8)

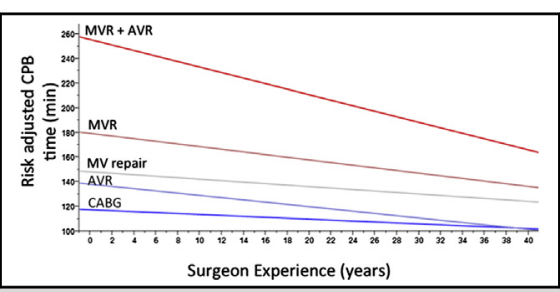

Risk-adjusted cardiopulmonary bypass time decreases with increasing surgical experience.

Central Message

Years in practice is a metric of surgeon experience that independently predicts operative efficiency and long-term survival in cardiac surgery valve procedures.

\section{Perspective}

Whereas competence in cardiac surgery can be achieved in the current era of surgical training programs, excellence and mastery requires further postgraduate experience. Less common and more complex cardiac surgical procedures may require additional training and/or experience to achieve excellent outcomes. See Editorial Commentary page 1069.

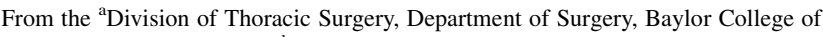
Medicine, Houston, Tex; ${ }^{b}$ Division of Cardiac Surgery, Department of Surgery, The Brigham and Women's Hospital, Boston, Mass; and ' Harvard Business School, Harvard University, Boston, Mass.

Read at the 95th Annual Meeting of The American Association for Thoracic Surgery, Seattle, Washington, April 25-29, 2015.

Received for publication June 3, 2014; revisions received June 23, 2015; accepted for publication July 17, 2015; available ahead of print Sept 15, 2015.

Address for reprints: John G. Byrne, MD, Division of Cardiac Surgery, Department of Surgery, Brigham and Women's Hospital, 75 Francis St, Boston, MA 02115 (E-mail: jbyrne@partners.org).

$0022-5223 / \$ 36.00$

Copyright (C) 2015 by The American Association for Thoracic Surgery

http://dx.doi.org/10.1016/j.jtcvs.2015.07.068
} 


\section{Abbreviations and Acronyms \\ AVR = aortic valve replacement \\ $\mathrm{CABG}=$ coronary artery bypass grafting \\ $\mathrm{CPB}=$ cardiopulmonary bypass \\ MVR $=$ mitral valve replacement \\ MV $=$ mitral valve}

career. ${ }^{1,2}$ In line with these observations, our group recently reported that attending cardiac surgeon experience (ie, years since fellowship graduation) was significantly associated with a reduction in cardiopulmonary bypass (CPB) and crossclamp times in coronary artery bypass grafting (CABG) procedures. ${ }^{2}$ There is a large body of literature on the effects of individual surgeon volume on perioperative morbidity and mortality following surgical procedures. For the majority of cardiac operations, the balance of evidence suggests that higher individual surgeon volume is associated with improved postoperative morbidity and mortality, ${ }^{3-9}$ although there are some studies that fail to demonstrate this relationship. ${ }^{8,10-12}$ The effect of surgeon experience on learning curves of operative proficiency across a range of standard cardiac surgical procedures has not been formally tested. Further, the effect of surgeon experience on long-term survival across this range of cardiac surgical procedures has not yet been examined. We hypothesized that increased postgraduate surgical experience would correlate with improved operative efficiency (CPB and crossclamp times), and longterm survival in a variety of standard cardiac surgical procedures.

\section{METHODS}

From a prospectively collected, retrospective institutional database we identified all isolated CABG, aortic valve replacement (AVR), mitral valve (MV) repair, mitral valve replacement (MVR), and MVR + AVR (double valve) procedures performed at a single institution from January 1, 2002, through June 30, 2012. Preoperative, operative, and postoperative characteristics were captured in this prospectively collected database modeled after the Society of Thoracic Surgeons national database criteria. ${ }^{13}$ Overall survival data were collected using a combination of the Social Security Death Index and institutional follow-up data. Surgeon experience was defined as the number of years since cardiothoracic fellowship graduation on the date of the procedure. Our study was approved by the Brigham and Women's Hospital institutional review board.

\section{Statistical Analysis}

All statistical analyses were performed using SAS software (SAS Institute Inc, Cary, NC). The primary dependent variables included CPB time, crossclamp time, 30-day mortality, and overall survival. To create a patientlevel summary measure of case severity and identify significant predictors of CPB time, crossclamp time, and survival were evaluated. Multivariable linear regression was used for $\mathrm{CPB}$ and crossclamp time end points. Multivariable logistic regression was used for the 30-day mortality, a binary variable. Cox proportional hazards regression analyses were used for long-term time-dependent data.
Covariates for predicting CPB time, crossclamp time, and survival measures included patient age, sex, body mass index, height, weight, ejection fraction, unstable angina (ie, no myocardial infarction $<7$ days), myocardial infarction, cardiogenic shock, congestive heart failure/New York Heart Association functional class, cerebrovascular disease/cerebrovascular accident, diabetes, preoperative dialysis, preoperative creatinine level, operative urgency status, preoperative arrhythmia, chronic obstructive pulmonary disease (ie, stage 3 or 4 chronic lung disease), current smoking status, reoperation, and previous cardiovascular intervention. Covariates were selected on the basis of having a previously documented association with the length of CPB time, crossclamp time, or mortality ${ }^{14}$ and a low rate of missing data. Model selection to create a robust multivariable patient risk adjustment model independently for $\mathrm{CPB}$, crossclamp time, and overall survival was performed using the approach described by Collett. ${ }^{15}$ Each procedure was evaluated as a separate model. Briefly, following univariate analysis for each preoperative and operative predictor, those with a parameter $P$ value $<.15$ were selected for initial entry into the multivariable model. After initial fitting, nonsignificant variables were eliminated using backward selection $(P<.1)$. Nonsignificant univariate predictors were subsequently tested using forward selection $(P=.1)$ and all possible 2-way interactions were tested using forward selection ( $P=.1$ for entering). Finally, all nonsignificant main effects (unless a component of an interaction term) and nonsignificant interactions were removed. Patients with missing preoperative, intraoperative, or immediate postoperative data had data points imputed using a multiple imputation model. Patients with missing follow-up data were excluded from their respective end point analyses.

Following adjustment of patient risk characteristics and surgeon effects using fixed effects modeling by surgeon level, attending surgeon experience was entered into each model (ie, CPB time, crossclamp time, 30-day mortality, and overall survival) as a continuous variable. For continuous end points, the expected performance curve of surgical teams over time was generated based on a multivariable generalized estimating equation regression model. CPB time, crossclamp time, and overall survival were the outcomes of interest, whereas attending experience was the predictor, and patient case mix was considered as covariate in the final model. The raw transformation of the surgeon experience variable was used in all of our procedure models. Because the CPB and crossclamp time curves may not necessarily be a linear function of surgeon experience, we also considered models with quadratic or logarithmic terms in surgeon experience and chose the model with the best fit.

\section{RESULTS}

Our patient cohort included 6591 patients who underwent 3726 CABG (56.5\%), 1626 AVR (24.7\%), 731 MV repair (11.1\%), 324 MVR (4.9\%), and 184 MVR + AVR (2.8\%) procedures. Mean patient age was $66 \pm 12$ years and $67.8 \%$ of patients were men. Patient risk factors and characteristics for each procedure are shown in Table 1 . There were 10 surgeons with varying years of postgraduate experience. The mean surgeon years of experience was $16.0 \pm 11.7$ years, with a range of 1.04 to 35.18 years. The total number of cases performed by an individual surgeon over the period of study ranged from 75 to 1660 , and the case mix stratified by years of surgeon experience is shown in Table 2 .

To test whether CPB and crossclamp times are influenced by surgeon experience in AVR, MV repair, MVR, and MVR + AVR procedures in a similar way that we have shown to be true for CABG procedures, ${ }^{2}$ we constructed patient risk-adjusted and surgeon-level fixed effects adjusted CPB time and crossclamp time experience curves for each 
TABLE 1. Patient characteristics

\begin{tabular}{|c|c|c|c|c|c|}
\hline Characteristic & CABG & AVR & MV repair & MVR & $\mathbf{M V R}+\mathbf{A V R}$ \\
\hline Age (y) & $66 \pm 11$ & $69 \pm 14$ & $58 \pm 13$ & $63 \pm 15$ & $64 \pm 14$ \\
\hline Male & 76 & 56 & 64 & 40 & 52 \\
\hline Body mass index & $29 \pm 5$ & $28 \pm 6$ & $25 \pm 4$ & $27 \pm 6$ & $27 \pm 6$ \\
\hline Height $(\mathrm{cm})$ & $172 \pm 10$ & $169 \pm 11$ & $173 \pm 10$ & $167 \pm 10$ & $169 \pm 11$ \\
\hline Weight $(\mathrm{kg})$ & $86 \pm 18$ & $81 \pm 19$ & $76 \pm 15$ & $76 \pm 20$ & $76 \pm 19$ \\
\hline Ejection fraction $(\%)$ & $58 \pm 10$ & $56 \pm 11$ & $61 \pm 8$ & $56 \pm 12$ & $57 \pm 11$ \\
\hline Angina & 72 & 19 & 6 & 10 & 12 \\
\hline Myocardial infarction & 45 & 10 & 3 & 11 & 4 \\
\hline Family history of coronary artery disease & 30 & 20 & 18 & 19 & 19 \\
\hline Congestive heart failure & 25 & 36 & 24 & 59 & 59 \\
\hline Cardiogenic shock & 2 & 1 & 0 & 3 & 0 \\
\hline \multicolumn{6}{|l|}{ New York Heart Association functional class } \\
\hline 1 & 19 & 15 & 33 & 10 & 8 \\
\hline 2 & 44 & 45 & 45 & 32 & 35 \\
\hline 3 & 29 & 36 & 21 & 50 & 57 \\
\hline 4 & 8 & 4 & 1 & 8 & 1 \\
\hline Arrhythmia & 5 & 9 & 8 & 22 & 21 \\
\hline Cardiovascular accident & 5 & 4 & 1 & 10 & 9 \\
\hline Cerebrovascular disease & 12 & 10 & 4 & 15 & 16 \\
\hline Diabetes & 38 & 20 & 4 & 18 & 21 \\
\hline Chronic obstructive pulmonary disease & 10 & 16 & 10 & 23 & 26 \\
\hline Current or previous smoker & 59 & 45 & 33 & 45 & 49 \\
\hline \multicolumn{6}{|l|}{ Operative urgency } \\
\hline Elective & 44 & 83 & 94 & 68 & 67 \\
\hline Urgent & 52 & 16 & 6 & 27 & 30 \\
\hline Emergent & 4 & 1 & 0 & 5 & 3 \\
\hline Reoperation & 14 & 19 & 4 & 43 & 47 \\
\hline Creatinine & $1.1 \pm 0.8$ & $10.8 \pm 0.6$ & $1.0 \pm 0.4$ & $1.2 \pm 0.9$ & $1.4 \pm 1.4$ \\
\hline
\end{tabular}

Values are shown as mean \pm standard deviation or \%. $C A B G$, Coronary artery bypass grafting; $A V R$, aortic valve replacement; $M V$, mitral valve; $M V R$, mitral valve replacement.

of these procedures (Figures 1, $A$ and 2, A). Scatter plot readouts of the linear regression analyses from which these curves are derived are shown in Figures E1 and E2. For all procedures, the mean CPB times were $112.5 \pm 48.7$ minutes (range, 16-596 minutes) and the mean crossclamp times were $81.7 \pm 33.9$ minutes (range, 8-386 minutes). The procedures had markedly different efficiency learning curves for both CPB time and crossclamp time. For CPB time, the learning curve for each procedure was characterized by a statistically significant improvement with increasing postgraduate surgical experience $(\beta$ coefficient was -0.33 for CABG, -0.89 for AVR, -1.30 for MV repair, -1.51 for MVR, and -2.22 for MVR + AVR; $P<.001$ for all procedures). For crossclamp time, the learning curve for each procedure was characterized by a statistically significant improvement with increasing postgraduate surgical experience ( $\beta$ coefficient was -0.44 for $\mathrm{CABG},-0.83$ for AVR, -1.11 for MV repair, -0.87 for MVR, and -2.01 for MVR + AVR; $P<.001$ for all procedures). To determine the predictive effect of surgical experience, $R^{2}$ values were measured after adjusting for patient risk and surgeon-level fixed effects, and before the addition of surgical experience as well as after the addition of surgeon experience (Figures 1, $B$ and 2, B). There was marginal improvement in the predictability of CPB and crossclamp time for $\mathrm{CABG}$ with the addition of surgical experience; however, the addition of surgeon experienced markedly increased the adjusted $R^{2}$ value (explanatory variability in predicting CPB and crossclamp times) in AVR, MV repair, MVR, and MVR + AVR.

The unadjusted overall 30 -day mortality was $1.3 \%$ for CABG, $2.4 \%$ for AVR, $0.7 \%$ for MV repair, $4.3 \%$ for MVR, and $4.9 \%$ for MVR + AVR. The mean follow-up time was $5 \pm 3$ years and the total patient years available for analyses were 32,098 years. To determine whether surgeon experience influenced 30-day mortality in these procedures, logistic regression models were constructed for each procedure (Table 3). Controlling for patient risk and surgeon-level fixed effects, these analyses revealed an independent predictive effect of surgeon experience on 30-day mortality in the 3 least common procedures performed during this time period, MV repair (odds ratio [OR], 0.63; $P<.0001)$, MVR (OR, 0.73; $P=.001)$, and MVR + AVR (OR, 0.86; $P=.0004)$, and did not influence 30-day mortality in CABG or AVR procedures. To 
TABLE 2. Postgraduate surgeon experience and number of cases performed

\begin{tabular}{|c|c|c|c|c|c|c|}
\hline $\begin{array}{c}\text { Years of } \\
\text { experience }\end{array}$ & Total cases & CABG & AVR & MV repair & MVR & MVR + AVR \\
\hline 1 & 301 & 233 & 47 & 9 & 8 & 4 \\
\hline 2 & 304 & 258 & 33 & 8 & 5 & 0 \\
\hline 3 & 297 & 226 & 42 & 13 & 8 & 8 \\
\hline 4 & 352 & 253 & 73 & 10 & 10 & 6 \\
\hline 5 & 429 & 307 & 84 & 20 & 10 & 8 \\
\hline 6 & 343 & 234 & 79 & 14 & 8 & 8 \\
\hline 7 & 127 & 51 & 47 & 10 & 15 & 4 \\
\hline 10 & 103 & 72 & 27 & 1 & 3 & 0 \\
\hline 11 & 139 & 119 & 11 & 3 & 2 & 4 \\
\hline 12 & 206 & 175 & 20 & 4 & 5 & 2 \\
\hline 13 & 209 & 154 & 36 & 5 & 12 & 2 \\
\hline 14 & 353 & 271 & 52 & 11 & 11 & 8 \\
\hline 15 & 434 & 331 & 60 & 15 & 12 & 16 \\
\hline 16 & 318 & 205 & 64 & 25 & 18 & 6 \\
\hline 17 & 278 & 192 & 49 & 14 & 13 & 10 \\
\hline 18 & 234 & 163 & 45 & 16 & 10 & 0 \\
\hline 19 & 200 & 130 & 47 & 14 & 7 & 2 \\
\hline 20 & 147 & 86 & 34 & 12 & 11 & 4 \\
\hline 21 & 55 & 18 & 21 & 7 & 3 & 6 \\
\hline 22 & 51 & 17 & 17 & 9 & 4 & 4 \\
\hline 23 & 64 & 22 & 25 & 11 & 4 & 2 \\
\hline 24 & 40 & 18 & 14 & 7 & 1 & 0 \\
\hline 25 & 45 & 16 & 10 & 7 & 6 & 6 \\
\hline 26 & 47 & 3 & 25 & 12 & 3 & 4 \\
\hline 27 & 37 & 6 & 17 & 6 & 4 & 4 \\
\hline 28 & 32 & 8 & 15 & 5 & 2 & 2 \\
\hline 29 & 1 & 0 & 1 & 0 & 0 & 0 \\
\hline 30 & 79 & 22 & 22 & 24 & 11 & 0 \\
\hline 31 & 149 & 33 & 55 & 48 & 11 & 2 \\
\hline 32 & 165 & 29 & 68 & 59 & 5 & 4 \\
\hline 33 & 201 & 26 & 100 & 55 & 16 & 4 \\
\hline 34 & 194 & 14 & 78 & 84 & 16 & 2 \\
\hline 35 & 657 & 34 & 308 & 193 & 70 & 52 \\
\hline
\end{tabular}

$C A B G$, Coronary artery bypass grafting; $A V R$, aortic valve replacement; $M V$, mitral valve; $M V R$, mitral valve replacement.

determine whether surgeon experience influenced longterm survival in each of the 5 procedures, linear regression models were constructed for each procedure with overall survival as the outcome variable (Table 4). Controlling for patient risk and surgeon-level fixed effects, these analyses revealed an independent predictive effect of surgeon experience on long-term survival in AVR (hazard ratio [HR], $0.85 ; P<.0001$ ), MV repair (HR, 0.73; $P<.0001)$, and MVR + AVR (HR, $0.95 ; P=.006)$. There was a trend toward a significant effect of the influence of surgeon experience on long-term survival following $\operatorname{MVR}(P=.09)$ and no significant effect of surgeon experience on long-term survival in CABG $(P=.15)$. Unadjusted survival at 3 years based on years of surgeon experience is shown for each procedure in Figure E3.

In addition to the surgeon experience metric of postgraduate years of experience, we examined cumulative case volume as a predictor of long-term survival for each separate procedure. These results are shown in Table E1 and reveal that cumulative case volume was a significant predictor of long-term survival in AVR and MV repair procedures.

\section{DISCUSSION}

Our principal finding is that postgraduate surgical experience drives not only operative efficiency, but also longterm survival in cardiac surgery valve procedures. These data have important implications for models of postgraduate learning that include apprenticeship and simulation training.

It is reasonable to propose that increasing surgeon experience correlates positively with improved surgical technique, and it is our opinion that surgical technique directly influences long-term survival outcomes in cardiac surgery. Technical proficiency likely relates to durability of valve repair and graft patency, and these factors likely translate into advantages, or disadvantages, in long-term survival.

The metric of surgeon experience that we examined in this study was time since postgraduate training. Compared with more widely studied learning curve metrics such as case volume, we believe that years since postgraduate training may capture intangible factors related to surgical acumen and judgment. Whereas time since postgraduate training has not been thoroughly studied as a predictor of short-term outcomes in cardiac surgery, it has been previously shown in a single institution study that lower academic seniority was associated with longer CABG operative times, perfusion times, and crossclamp times, but not with postoperative morbidity or mortality. ${ }^{16}$ The groups that were compared in this study were faculty and first- and second-year cardiothoracic fellows; experience as a faculty member was not examined.

A large body of literature has established a positive relationship between hospital volume and short-term operative morbidity and mortality across a variety of medical and surgical procedures. Importantly, recent evidence suggests that the associations between hospital volume and surgical mortality are mediated by surgeon volume, ${ }^{3}$ and surgeon volume has, in fact, been found to have a greater influence on patient outcomes than hospital volume. ${ }^{17}$ In cardiac surgery, specifically, increasing surgeon volume has been associated with improved postoperative morbidity and mortality in on-pump $\mathrm{CABG},{ }^{3,6-8}$ off-pump $\mathrm{CABG},{ }^{9} \mathrm{AVR},{ }^{3,4}$ and minimally invasive mitral valve surgery. ${ }^{5}$

To the best of our knowledge, this is the first report to rigorously examine years since postgraduate training as a predictor of long-term survival in cardiac surgery procedures. Our hypothesis was that this metric of surgeon experience would correlate with improved overall survival. In AVR, MV repair, and MVR + AVR, we found years since postgraduate training to be an independent predictor of 


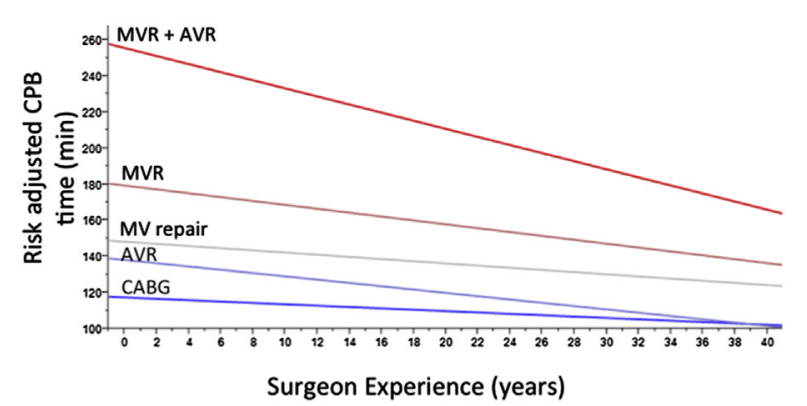

A

B

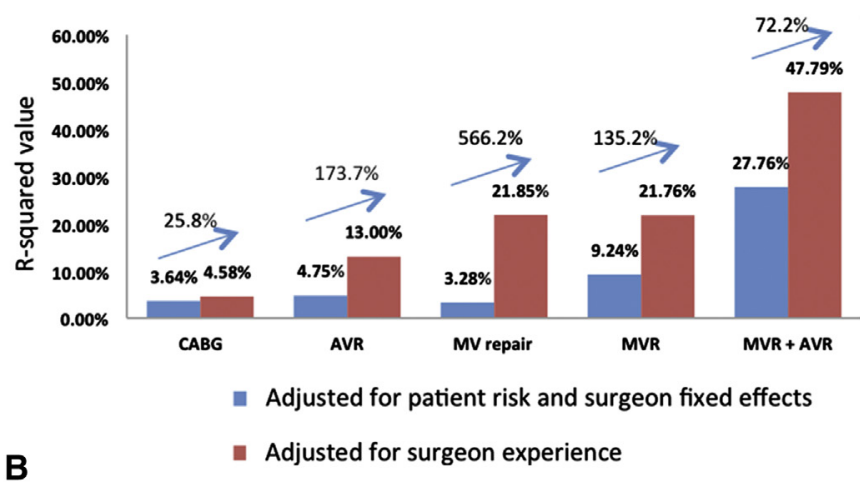

- Adjusted for surgeon experience

FIGURE 1. A, Risk-adjusted cardiopulmonary bypass $(C P B)$ time (in minutes) with respect to years of surgical experience for each procedure. All experience curves have $P<.001$. B, Best-fit CPB models are shown with $R^{2}$ values adjusted for patient risk and surgeon-level fixed effects (blue), and additionally adjusted for surgeon experience (red). $M V R$, Mitral valve replacement; $A V R$, aortic valve replacement; $M V$, mitral valve; $C A B G$, coronary artery bypass grafting.

long-term survival, and we found a similar trend for MVR procedures. Separately, we examined an additional metric of surgeon experience, cumulative case volume, and found that case volume was predictive of long-term survival in AVR and MV repair operations, but not in MVR, MVR + AVR operations, or CABG operations. Taken together, these data suggest that years since postgraduate training and cumulative case volume are different surgeon experience metrics with different predictive abilities in cardiac surgery procedures. In our dataset, years since postgraduate experience correlated with long-term survival in a greater range of valve procedures than did cumulative case volume.

It is noteworthy that surgeon experience was not associated with statistically significant improvements in longterm (or 30-day) mortality following CABG procedures. Similarly, the magnitude of improvement in CPB and crossclamp time was only clinically meaningful for
AVR, MV repair, MVR, and MVR + AVR procedures, and not for CABG. In our study, CABG was by far the most common of all performed procedures $(57 \%)$ ). One interpretation of these data is surgical maturity is attained for this procedure during cardiothoracic fellowship and this decreases the surgical learning curve during a surgeon's faculty career. The influence of training on this procedure is highlighted in a recent publication by our group ${ }^{2}$ that demonstrated that the cumulative experience of attending cardiac surgeons and cardiothoracic fellows had a dramatic effect on CPB and crossclamp times, and that the influence of attending-fellow pair experience far exceeded the influence of individual surgeon experience. Another potential explanation for this finding is that $\mathrm{CABG}$ is a mature technology whose basic underlying principles are familiar to graduates of surgical training programs and may, therefore, require less of a learning curve today than during previous decades.
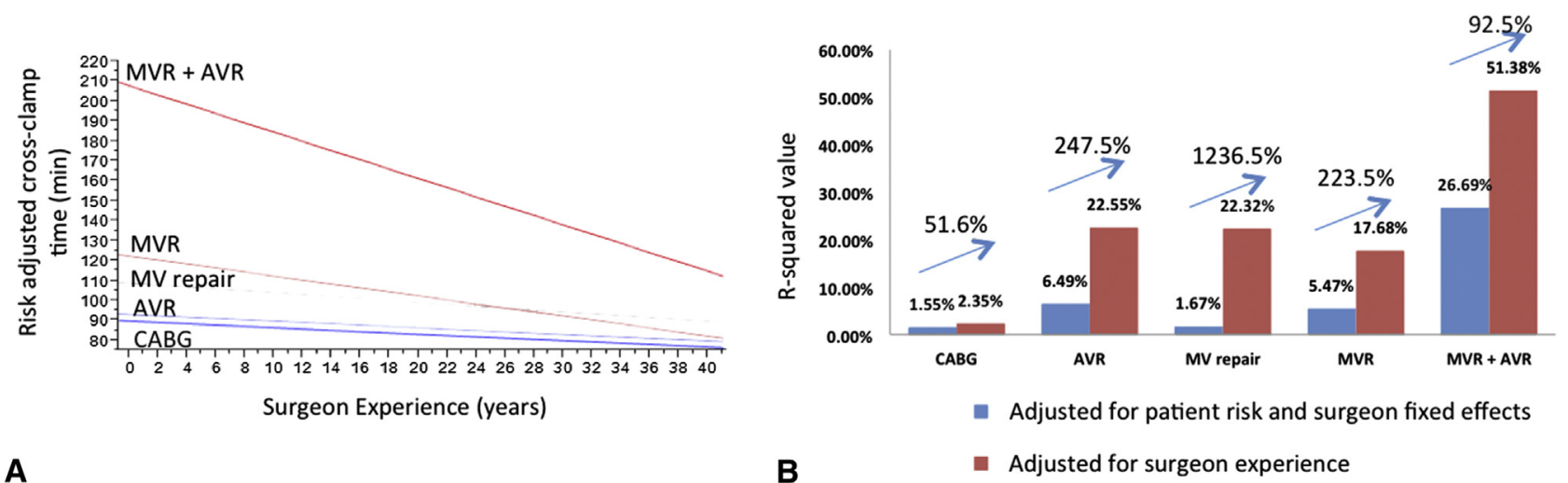

A

FIGURE 2. A, Risk-adjusted crossclamp time (in minutes) with respect to years of surgical experience for each procedure. All experience curves have $P<.001$. B, Best-fit crossclamp models are shown with $R^{2}$ values adjusted for patient risk and surgeon-level fixed effects (blue), and additionally adjusted for surgeon experience (red). $M V R$, Mitral valve replacement; $A V R$, aortic valve replacement; $M V$, mitral valve; $C A B G$, coronary artery bypass grafting. 
TABLE 3. Independent effect of surgeon experience on 30-day mortality

\begin{tabular}{|c|c|c|c|}
\hline Operation & Odds ratio & Confidence interval & $P$ value \\
\hline $\begin{array}{l}\text { Coronary artery bypass } \\
\text { grafting* }\end{array}$ & 1.022 & $0.951-1.097$ & .5525 \\
\hline Aortic valve repair $\dagger$ & 0.995 & $0.918-1.079$ & .9011 \\
\hline Mitral valve repair $\neq$ & 0.633 & $0.534-0.750$ & $<.0001$ \\
\hline Mitral valve replacement $\S$ & 0.732 & $0.607-0.883$ & .001 \\
\hline $\begin{array}{l}\text { Aortic valve } \\
\text { replacement }+ \text { mitral valve } \\
\text { replacement }\end{array}$ & 0.863 & $0.795-0.936$ & .0004 \\
\hline
\end{tabular}

Surgeon experience was corrected for the following additional variables predictive of 30-d survival in multivariable analyses in each model. *Cerebrovascular accident and reoperation. $\dagger$ Age, angina, creatinine, ejection fraction, and current smoker. $\ddagger$ Age, reoperation, and urgent/emergent operation. $\S$ Ejection fraction, reoperation, and emergent operation. ||Congestive heart failure and creatinine.

An additional element to take into consideration is that, although our study is not focused on gaps in recent surgical training, surgical training has certainly changed over the course of the past 35 years, which was the span of surgical experience in our dataset. If it is assumed that there is no meaningful difference in individual surgical learning curves among different eras of surgical training, this implies that either surgical training in valve procedures has not been as effective as it was for coronary revascularization procedures, or that the complexity and rapid evolution in valvular procedures may be responsible for the dichotomy between the $\mathrm{CABG}$ and valve data. Our study is not aimed at examining the effects of surgical training on surgical outcomes, but is focused on surgeon experience following cardiothoracic surgery residency. It is our opinion that competence in cardiac surgery can be achieved in the current era of surgical training programs; however, excellence and mastery requires further postgraduate experience.

The strengths of our study include the robust prospectively collected database from which it is derived and

TABLE 4. Independent effect of surgeon experience on long-term survival

\begin{tabular}{lclc}
\hline \multicolumn{1}{c}{ Operation } & Hazard ratio & Confidence interval & $\boldsymbol{P}$ value \\
\hline $\begin{array}{l}\text { Coronary artery bypass } \\
\text { grafting* }\end{array}$ & 0.802 & $0.593-1.083$ & .15 \\
Aortic valve repair $\dagger$ & 0.852 & $0.801-0.906$ & $<.0001$ \\
Mitral valve repair $\ddagger$ & 0.732 & $0.627-0.854$ & $<.0001$ \\
Mitral valve replacement $\S$ & 0.874 & $0.748-1.021$ & .09 \\
Aortic valve & 0.947 & $0.910-0.985$ & .006 \\
$\quad$ replacement + mitral & & & \\
$\quad$ valve replacement $\|$ & & & \\
\hline
\end{tabular}

Surgeon experience was corrected for the following additional variables predictive of long-term survival in multivariable analyses in each model. *Congestive heart failure, cerebrovascular accident, cardiogenic shock, height $(\mathrm{cm})$, myocardial infarction, and previous cardiac surgical procedures. $\nmid$ Age, angina, last creatinine, ejection fraction (low), and current smoking. $\ddagger$ Age, previous cardiovascular intervention, and urgent/ emergent operation. §Cardiogenic shock and current smoking. ||Congestive heart failure and last creatinine. complete long-term follow-up on a large cohort of patients operated on by 10 surgeons with a wide variance in years of experience. Our study is limited by the selection and information biases inherent to retrospective analyses. Additionally, our study was performed at a single academic institution where different postgraduate year levels of residents are involved in these procedures, and this may account for some degree of confounding in our study that was not measured. Accordingly, our data may not be representative of the majority of cardiac surgery that is routinely performed in the United States. Several other elements of our dataset deserve mention as potential limitations. First, there was some variability in the total number of cases and number of specific cases performed by surgeons with similar levels of experience, which may have influenced our results. Additionally, the majority of AVRs (62\%) and MV repairs $(58 \%)$ were performed via hemisternotomy. At our institution, these procedures are typically performed by more experienced valve surgeons, and we believe that the performance of such procedures likely reflects and evolution of a surgeon as he or she progresses along his or her learning curve.

\section{CONCLUSIONS}

Increasing years of surgeon experience is associated with improved operative efficiency and long-term mortality in valvular cardiac surgery. It is our opinion that cardiothoracic training programs appear to provide adequate training in CABG procedures. Less-common and more-complex procedures may require further training to achieve excellent outcomes. A similar phenomenon may occur with CABG as it is supplanted by improved interventional techniques and used on increasingly complex patients. Also implied by our data is that learning curves are more likely to exist when new technologies such as robotics or new procedures such as transaortic/transapical aortic valves, ${ }^{18,19}$ minimally invasive $\mathrm{CABG},{ }^{20,21}$ or minimally invasive mitral valve surgery ${ }^{5}$ are introduced into a surgeon's repertoire.

\section{Conflict of Interest Statement}

Authors have nothing to disclose with regard to commercial support.

You can watch a Webcast of this AATS meeting presentation by going to: http://webcast.aats.org/2014/files/Monday/ 20140428_335PM_355PM_Andrew_ElBardissi.mp4.

\section{References}

1. Carty MJ, Chan R, Huckman R, Snow D, Orgill DP. A detailed analysis of the reduction mammaplasty learning curve: a statistical process model for approaching surgical performance improvement. Plast Reconstruct Surg. 2009;124: 706-14. 
2. Elbardissi AW, Duclos A, Rawn JD, Orgill DP, Carty MJ. Cumulative team experience matters more than individual surgeon experience in cardiac surgery. $J$ Thorac Cardiovasc Surg. 2013;145:328-33.

3. Birkmeyer JD, Stukel TA, Siewers AE, Goodney PP, Wennberg DE, Lucas FL. Surgeon volume and operative mortality in the United States. $N$ Engl J Med. 2003:349:2117-27.

4. Dewey TM, Herbert MA, Ryan WH, Brinkman WT, Smith R, Prince SL, et al. Influence of surgeon volume on outcomes with aortic valve replacement. Ann Thorac Surg. 2012;93:1107-12; discussion 12-3.

5. Holzhey DM, Seeburger J, Misfeld M, Borger MA, Mohr FW. Learning minimally invasive mitral valve surgery: a cumulative sum sequential probability analysis of 3895 operations from a single high-volume center. Circulation. 2013;128:483-91.

6. Wen HC, Tang CH, Lin HC, Tsai CS, Chen CS, Li CY. Association between surgeon and hospital volume in coronary artery bypass graft surgery outcomes: a population-based study. Ann Thorac Surg. 2006;81:835-42.

7. Hannan EL, Wu C, Ryan TJ, Bennett E, Culliford AT, Gold JP, et al. Do hospitals and surgeons with higher coronary artery bypass graft surgery volumes still have lower risk-adjusted mortality rates? Circulation. 2003;108: 795-801

8. Glance LG, Dick AW, Osler TM, Mukamel DB. The relation between surgeon volume and outcome following off-pump vs on-pump coronary artery bypass graft surgery. Chest. 2005;128:829-37.

9. Lapar DJ, Mery CM, Kozower BD, Kern JA, Kron IL, Stukenborg GJ, et al. The effect of surgeon volume on mortality for off-pump coronary artery bypass grafting. J Thorac Cardiovasc Surg. 2012;143:854-63.

10. Patel HJ, Herbert MA, Drake DH, Hanson EC, Theurer PF, Bell GF, et al. Aortic valve replacement: using a statewide cardiac surgical database identifies a procedural volume hinge point. Ann Thorac Surg. 2013;96:1560-5; discussion 5-6.

11. Astor BC, Kaczmarek RG, Hefflin B, Daley WR. Mortality after aortic valve replacement: results from a nationally representative database. Ann Thorac Surg. 2000; 70:1939-45.

12. Hughes RG, Hunt SS, Luft HS. Effects of surgeon volume and hospital volume on quality of care in hospitals. Med Care. 1987;25:489-503.

13. Variables in the Society of Thoracic Surgeons Cardiac Surgery National Database. http://www.sts.org/sts-national-database/database-managers/adult-cardiac-surgerydatabase. Accessed August 8, 2015.

14. Shahian DM, O’Brien SM, Filardo G, Ferraris VA, Haan CK, Rich JB, et al. The Society of Thoracic Surgeons 2008 cardiac surgery risk models: part 1-coronary artery bypass grafting surgery. Ann Thorac Surg. 2009;88: S2-22.

15. Collett D. Modelling survival data in medical research. Boca Raton: Chapman Hall/CRC; 2003.

16. Bakaeen FG, Dhaliwal AS, Chu D, Bozkurt B, Tsai P, LeMaire SA, et al. Does the level of experience of residents affect outcomes of coronary artery bypass surgery? Ann Thorac Surg. 2009;87:1127-33; discussion 33-4.

17. Chowdhury MM, Dagash H, Pierro A. A systematic review of the impact of volume of surgery and specialization on patient outcome. Br J Surg. 2007;94: 145-61.

18. Alli OO, Booker JD, Lennon RJ, Greason KL, Rihal CS, Holmes DR Jr. Transcatheter aortic valve implantation: assessing the learning curve. JACC Cardiovasc Intervent. 2012:5:72-9.

19. Kempfert J, Rastan A, Holzhey D, Linke A, Schuler G, van Linden A, et al. Transapical aortic valve implantation: analysis of risk factors and learning experience in 299 patients. Circulation. 2011;124(Suppl):S124-9.

20. Une D, Lapierre H, Sohmer B, Rai V, Ruel M. Can minimally invasive coronary artery bypass grafting be initiated and practiced safely?: a learning curve analysis. Innovations. 2013;8:403-9.

21. Pisano G, Bohmer R, Edmondson A. Organizational differences in rates of learning: Evidence from the Adoption of Minimally Invasive Cardiac Surgery. Manage Sci. 2001;47:752-68.

Key Words: coronary artery bypass grafting, aortic valve replacement, mitral valve replacement, cardiopulmonary bypass, mitral valve, aortic valve, surgeon experience, learning curve

\section{Discussion}

Dr James Fann (Stanford, Calif). Dr Burt, you and your colleagues at Brigham are to be congratulated for using your database to generate a compelling analysis of a single institution's 10-year experience to address a highly relevant question; that is, whether increased postgraduate experience as measured in years or seniority correlates with improved operating efficiency and outcomes. You conclude that although residency programs provide adequate training in coronary artery bypass grafting, increased surgery experience in terms of years is associated with improved operative efficiency and long-term outcomes with regard to less commonly performed procedures.

At the risk of reducing the discussion to a primer on development of expertise and expert performance-the fact that the more one is trained and performs in an appropriately stressed environment the better one's outcomescan you provide additional insights into the training paradigm that could potentially lessen the disparity that you observed? That is, clearly the trainees at Brigham have vast experience in coronary artery bypass grafting. What would be helpful to know is what a trainee is actually exposed to in the less commonly performed procedures. A previous study by Connors and colleagues a few years ago demonstrated that after 2003 the average number of cases during the residency period is 111 coronary artery bypass grafting procedures and a total of 78 aortic or mitral valve procedures, and presumably fewer mitral valve surgeries than aortic valve surgeries. Do you have any information as to the number of these less-performed procedures that the junior faculty at Brigham participated in during their training, especially those with $<6$ years of experience? I propose that rather than the number of postgraduate years, the outcomes may be due to the absolute number of procedures performed. This is particularly important at a time when there is greater emphasis on operating room efficiency.

Dr Burt. I don't have data on the number of cases performed by the 10 faculty here when they were residents, so I can't really comment on that. It is probably similar to the total case mix that was performed during the 12 years, at least for the faculty members who were trained in major academic centers, where most of these were coronary artery bypass grafting procedures.

I agree that case mix may be more important than years of experience, but obviously greater years of experience will provide a greater number of cases requiring each of these procedures, which is the learning curve.

Dr Fann. Another interesting finding is that with surgeons who have more than 13 years of experience, the focus of each surgeon's practice has shifted to 1 particular type of operation. That is, there are 2 surgeons where more than 
$75 \%$ of their procedures were coronary artery bypass grafting, whereas the caseload of 2 other surgeons was cardiac valve surgery by a vast majority, either isolated or combined valve surgery. So the idea of superspecialization becomes relevant. Does superspecialization by senior surgeons factor into the analysis? Over the course of many years and even decades, 1 surgeon may focus on 1 particular operation, particularly 1 that he does very well and has very good outcomes. Wouldn't one expect the outcomes to be better if that is the predominant surgery that the surgeon performs?

It is critical to look at this not in number of years, but number of cases and to decide at what point does that curve start to flatten out in terms of disparity.

Dr Burt. That last point is a good, although our analysis should tease out some of those issues because we analyzed each operation separately. We started by looking at 1 operation and 1 variable in our analysis. The last variable was surgeon experience. So even if a surgeon was doing less of a particular operation, he or she was still being analyzed-not on the number of procedures they were performing but their experience time in general.

Dr Glenn Whitman (Baltimore, $M d$ ). This is a tremendous study with a great hypothesis; all of us understand how difficult it is to answer a question like this. But I think an important variable went unmentioned. It is more than conceivable that in every 1 of these cases, when the operation is difficult the senior surgeon does it himself as opposed to taking a resident physician through the case. Furthermore, a resident physician who is in his second or third year may be the primary operative surgeon as opposed to a first-year resident. And all 3 of these issues may be independent of the attending surgeon and his experience. Nevertheless, whether the attending surgeon is doing the procedure or helping somebody, as he or she gets older, he or she gets better.

Dr Burt. It is not something that we looked at, it's not something we have information on, and often that's not something that's written down anywhere. Ultimately the outcome of the patient is the responsibility of the attending surgeon. So, as you mentioned, whether they are doing it or whether they are taking somebody through it, their years of experience is important.

Dr Julian Gaer (Harefield, United Kingdom). I think actually it was a Hopkins surgeon, Halsted, who said speed is not an aim in surgery but merely the byproduct of good technique. I realize that is not the point you were trying to make, but there is a danger that the message that trainees will take away is that a fast operation is a good operation.
On our side of the Atlantic that sort of philosophy, which has come about for all sorts of reasons, has held up the development of a number of surgical techniques that have now been shown to have clear long-term benefits but undoubtedly take longer than some older, more expedient techniques. Examples of this include total arterial revascularization and reconstructive mitral valve surgery.

Dr Burt. I didn't show any analysis here that would suggest that. I didn't show that decreased cardiopulmonary bypass or crossclamp time are associated with survival. That is not in this research. I did show that increased surgeon experience decreases the time on cardiopulmonary bypass or with the clamp on, and we used those as a surrogate for operative efficiency. That was, at least here, separate from 30-day mortality or long-term survival analyses.

Dr Marc Ruel (Ottawa, Ontario, Canada). What does this tell us about minimally invasive cardiac surgery?

Dr Burt. These data suggest that there are learning curves for complex operations, and there are probably steeper learning curves for operations you performed fewer of when you were a resident. There are several publications on the learning curve for robotic cardiac surgery or new cardiac surgery-operations that are only recently adoptedthat surgeons never had any experience with in their training. It suggests that there are steeper learning curves for operations you have not had a lot of exposure to, and if you want to start doing a new operation there will be a learning curve, and that has implications for training and how that's done.

Dr Ruel. Any such data within your series?

Dr Burt. No.

Dr Barry Esrig (New York, NY). No one will argue with the fact that the more you do, the more proficient you get, but in terms of long-term outcomes, as part of that increased experience, where does judgment come in terms of preoperative evaluation and preoperative preparation? There are articles that talk about low-volume centers still achieving good outcomes based on excellent infrastructure. Can you address those issues?

Dr Burt. Obviously judgment and experience are tied very closely together, and judgment is 1 of those things that is hard to measure objectively. There are a lot of articles also that say that all of these publications based on high hospital volume achieving good outcomes-when you look at them more closely - it is because of better surgeon volume within that hospital achieving good outcomes. I think, at least from the data set we have, it is difficult to tease out judgment from experience. 

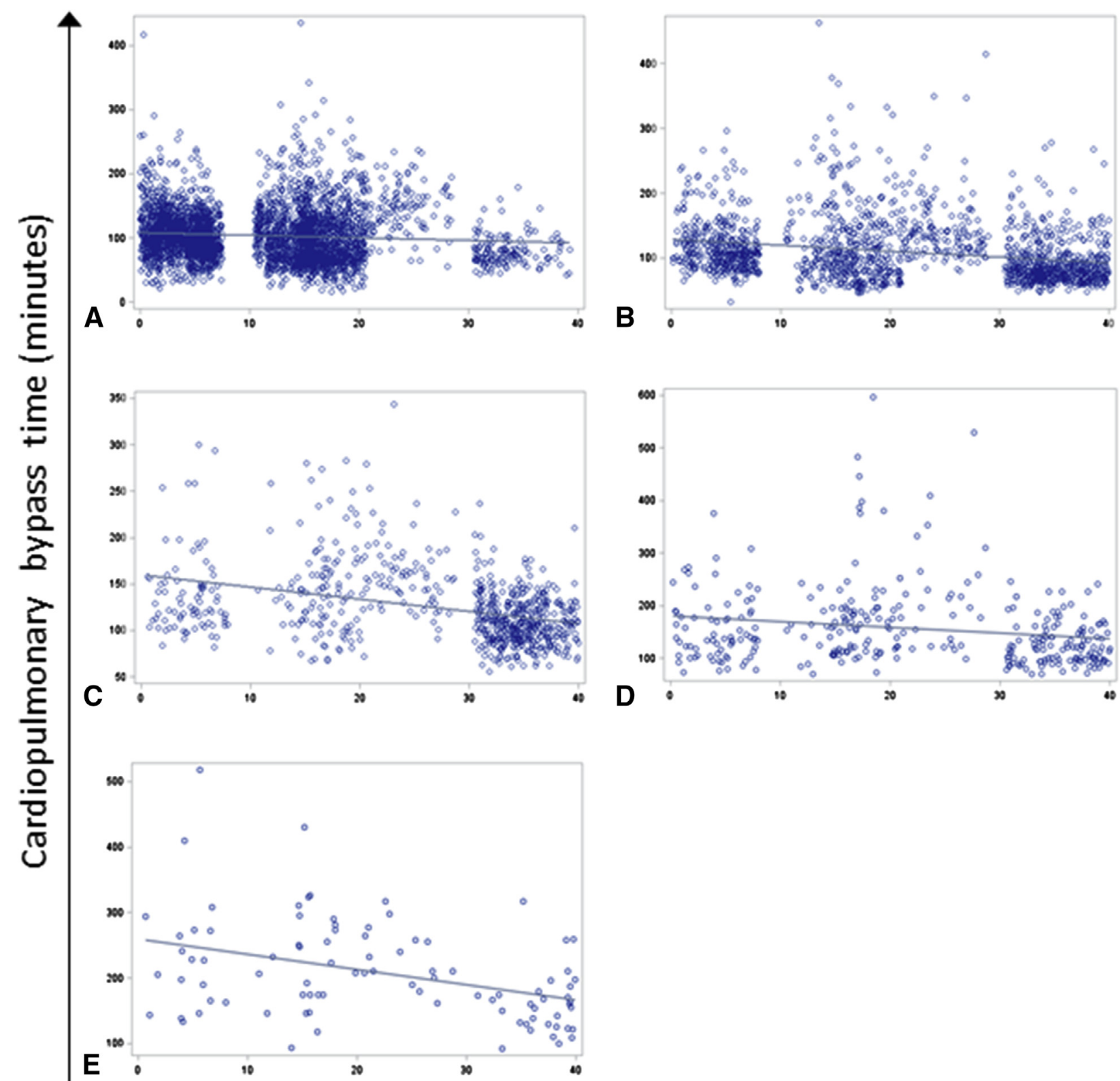

\section{Years since postgraduate training}

FIGURE E1. Scatter plots displaying results of linear regression analysis of cardiopulmonary bypass times for A, coronary artery bypass grafting; B, aortic valve repair; $\mathrm{C}$, mitral valve repair; $\mathrm{D}$, mitral valve replacement; and $\mathrm{E}$, mitral valve replacement + aortic valve replacement. 

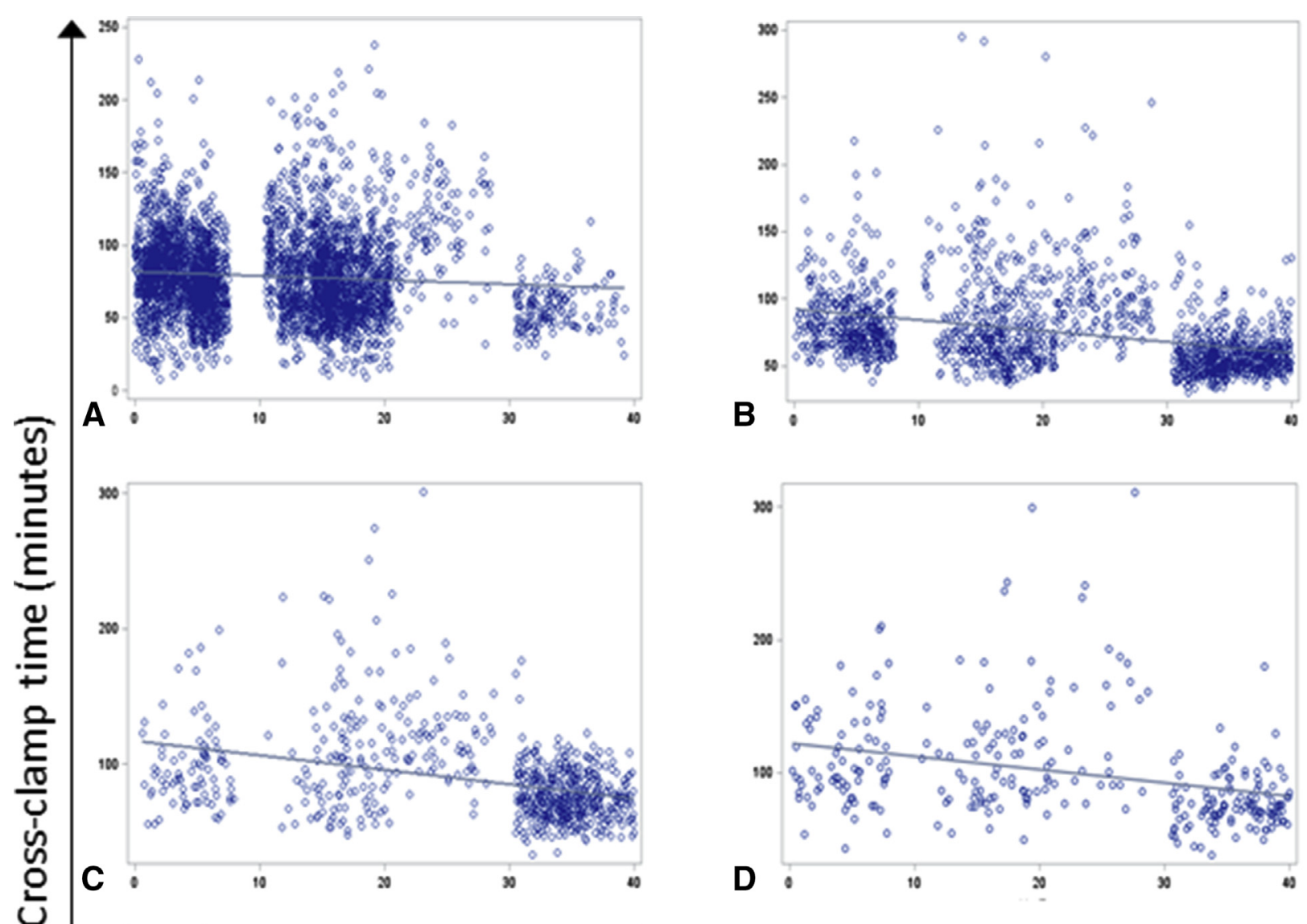

A 0

$$
\text { is }
$$
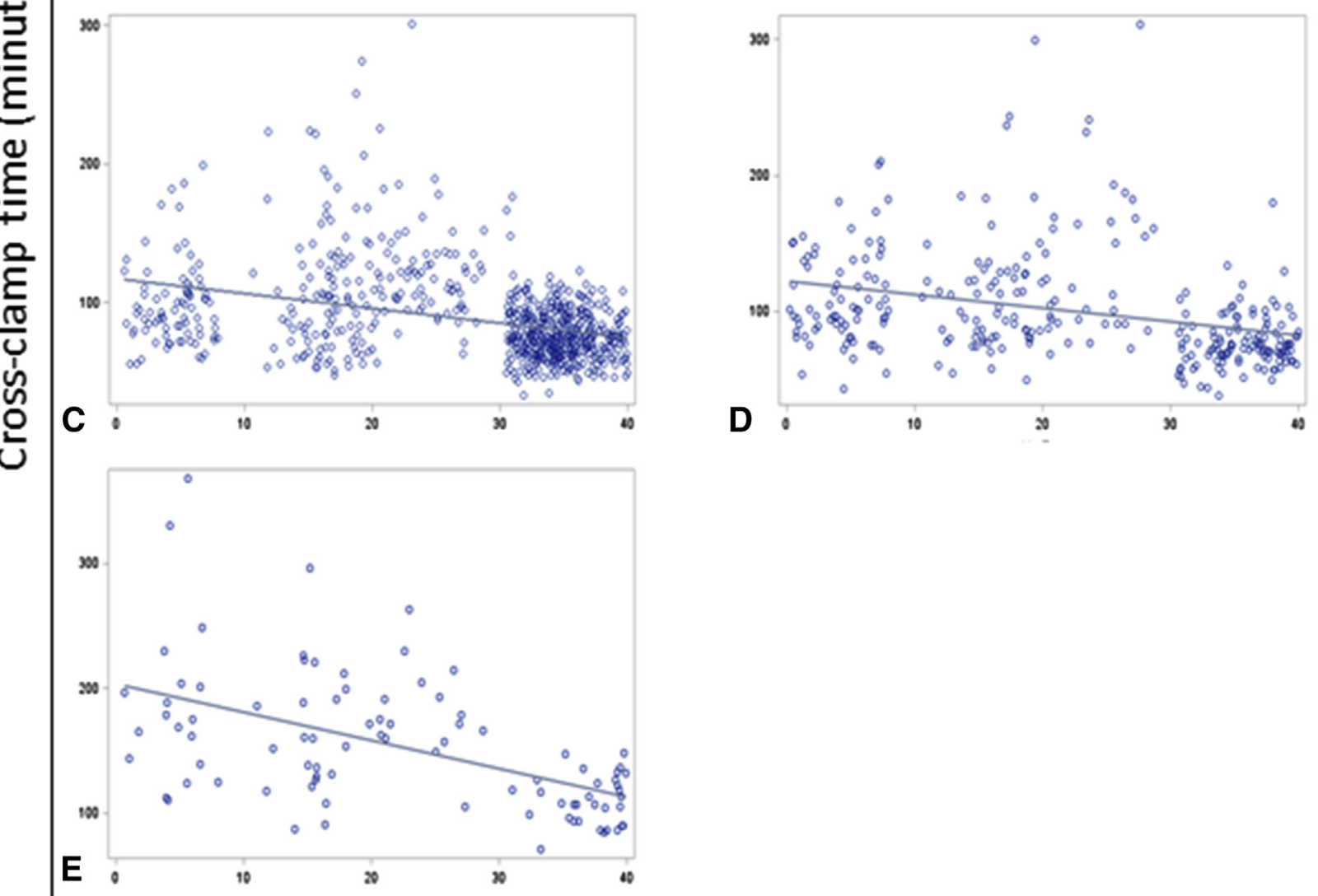

Years since postgraduate training

FIGURE E2. Scatter plots displaying results of linear regression analysis of crossclamp times for A, coronary artery bypass grafting; B, aortic valve repair; $\mathrm{C}$, mitral valve repair; $\mathrm{D}$, mitral valve replacement; and $\mathrm{E}$, mitral valve replacement + aortic valve replacement. 


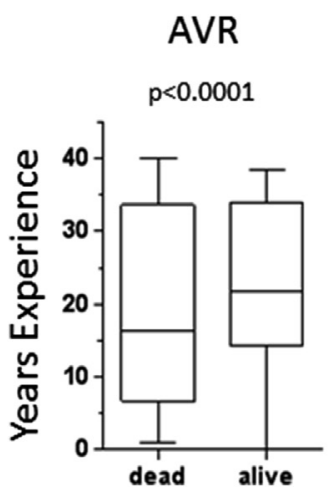

MV Repair

$p=0.006$

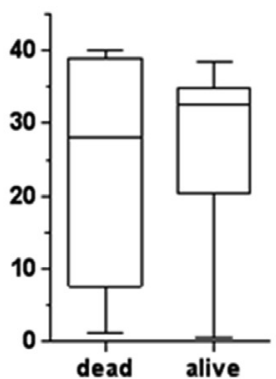

MVR

$p=0.7$

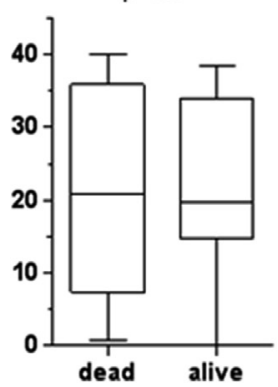

MVR+AVR

$\mathrm{p}=0.5$

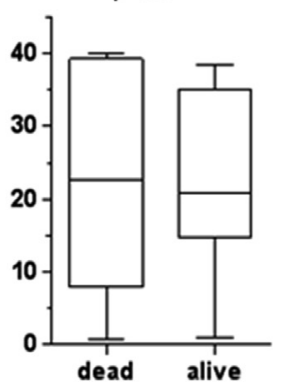

CABG

$\mathrm{p}=0.3$

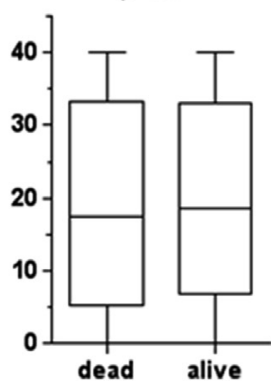

FIGURE E3. Survival at 3 years for each procedure, stratified by years of surgeon experience. $A V R$, Aortic valve replacement; $M V$, mitral valve; $M V R$, mitral valve replacement; $C A B G$, coronary artery bypass grafting.

TABLE E1. Effect of cumulative surgeon volume on long-term survival

\begin{tabular}{lclr}
\hline \multicolumn{1}{c}{ Operation } & Hazard ratio & Confidence interval & $\boldsymbol{P}$ value \\
\hline $\begin{array}{l}\text { Coronary artery bypass } \\
\text { grafting }\end{array}$ & 0.997 & $0.961-1.034$ & .8753 \\
Aortic valve replacement & 0.944 & $0.918-0.970$ & $<.0001$ \\
Mitral valve repair & 0.911 & $0.840-0.989$ & .0257 \\
Mitral valve replacement & 0.968 & $0.919-1.019$ & .2107 \\
$\begin{array}{l}\text { Aortic valve } \\
\quad \text { replacement }+ \text { mitral }\end{array}$ & 0.969 & $0.913-1.029$ & .3006 \\
$\quad$ & & & \\
\hline
\end{tabular}

